\title{
Outsourcing Strategy as a Viable Determinant of Organizational Performance: Evidence from Telecommunication Companies in Nigeria
}

\author{
Umar Abbas Ibrahim, $\mathrm{PhD}^{1} \&$ Anthony Onyekweli ${ }^{2}$ \\ ${ }^{1}$ Department of Business Administration, Nile University of Nigeria, Nigeria \\ Abbas.ibrahim@nileuniversity.edu.ng \\ ${ }^{2}$ Department of Business Administration, Nile University of Nigeria, Nigeria \\ tonyonyekweli@gmail.com
}

\begin{abstract}
The study aimed to determine how outsourcing core functions influence performance in relation to cost reduction, risk reduction, quality improvement and organizational efficiency of selected companies in the Nigeria telecommunications sector. Descriptive research design was adopted for the study, and census survey was used in determining the population made up 88 management and technical staff that are involved in outsourcing decisions and implementation. Structured questionnaires was used for data collection, and SPSS tool was used to quantitatively analyze the data using regression analysis to establish the relationship between outsourcing core functions, and performance of the organizations looking at cost reduction, risk reduction, quality improvement and organizational efficiency. The outcome indicated a strong positive relationship between Cost reduction and performance, weak positive relationship between Quality improvement, Organizational efficiency and performance, and a moderate positive relationship between Risk Reduction and performance The study therefore recommends that companies should concentrate on their core functions for competitive advantage and sustainability, and outsource non-core functions to free resources for value optimization, Firms should monitor outsourcing contracts for better performance, and conduct situational analysis before taking outsourcing decisions irrespective of whether they are core or non-core functions for efficiency and value optimization.
\end{abstract}

Keywords: Core functions, Cost Reduction Non- core functions, Outsourcing, Performance.

DOI: $10.7176 / \mathrm{EJBM} / 12-2-11$

Publication date: January $31^{\text {st }} 2020$

\section{Introduction}

\subsection{Introduction}

Outsourcing as a business model has gained relevance among companies as a strategy of addressing the challenges posed by the competitive and demanding business environment. The era of industrial revolution made companies more concerned on the best way to exploit their competitive advantage to be able to increase their markets and profit (Handfiel, 2006). Events like the 1970s' Arab-oil embargo in the USA have made firms recognize strategic role of sourcing and turned sourcing which was hitherto unimportant or clerical function to a highly skilled strategic function and component of strategic planning (Branemo, 2006). Notably, recessions suffered in history made companies seek for new ways of doing business for profitability and sustainability, and an underlying factor on profitability is cutting down on costs. The recognition is even greater now as many leading firms have considered cost control and supply management as important factors in maintaining competitiveness (Fantazy et al., 2009). The common approach at attaining cost cutting objective during the era was the transfer of services that were done internally to external parties at lower costs- Outsourcing.

Many studies on outsourcing presented its definition from different perspectives, but they all agreed that, it entails replacement of activities provided in-house by subcontracting them to other specialized firms for competitive advantage (Jae, Minh \& Shih, 2000), Domininquez, 2006; and Isaksoon \& Lantz, 2015). However, Handfield (2006) view outsourcing as the strategic use of outside resources to perform activities traditionally handled by internal staff and resources. According to Nilashai and Ghazali (2011), outsourcing is the shifting of internal process activity to an external body and it involves two or more parties, buyer and supplier or where there is the transfer of control of internal business activities to an external party (Kotabe et .at, 2012). The common denominator from the various definitions outline by different authors is that outsourcing involves allowing external party to carry out part of functions done internally by a firm. Globalization, competitive business environment and advancement in technology have made firms to look for ways of reducing cost and explore avenues of optimizing their internal resources (Hoetler, 2005). Today, businesses are exploring avenues for the shortest possible time to make returns on investments, taking into consideration investors' appetite for shorter 


\subsection{Statement of the research problem}

The Global economic meltdown, and other economic crises such as the great depression of 1929, oil shock of 1979, the US Mortgage crises of 2008 among others witnessed in the last decades, made firms to seek new ways of doing business. Studies have been carried out to under pin the causes of the crises, and how firms that survived were able to come out of the crises. According to a survey conducted by McKinsey (2008), the report indicated that $79 \%$ of companies that survived the crises adopted cost cutting measures in response to the economic crises through outsourcing. Though few studies have been conducted specifically on the impact of outsourcing on the performance of the Nigeria telecommunication sector, some of the studies are credited to Ogunsanmi (2013), John (2017). On the Anglophone West African sub-region, a study was done by Boison et.al, (2018) on the impact of outsourcing on the organizational performance: case study of Vodafone, Ghana. The study is similar to the present study, but done in another country.

The outcome of various studies on the impact of Outsourcing in the Telecommunication and manufacturing sector indicated varying results. John et, at. (2017), noted that previous studies have provided contradictory results on the impact of outsourcing on organizational performance. The findings of Elegbede (2013), Irefin, Olateju \& Hammed (2013), Suraju \& Hamed, (2013) and Gayamang Dallkins \& Abbey Brani, (2014), indicated that there was strong positive relationship between outsourcing and performance, however, the findings of Gilley K.M, Gutter C.R. and Rasheed A.A., 2004), Isakason \& Lantz, (2015) and Yeboah, (2013) could not establish any relationship between outsourcing and the performance of organizations. It should be noted that most of these studies were carried out in developed economies, and the findings may not be very applicable in developing economies like Nigeria with varying socio economic factors that affects businesses.

The Nigerian business environment is considered very competitive and aggressive. With the advent of the Mobile telecommunications in Nigeria in 2001, the sector has undergone various phases of changes and consequential challenges that led to the introduction of different business models by players within the sector to remain sustainable and profitable. It is remarkable to note that at the end of first quarter of 2016, the Nigeria Telecommunications Sector contributed N1,411,74 Billion to the Nigeria Gross Domestic Product (GDP) representing 8.83\% (Nigeria Communications Commission - NCC 2016), and at the end of second quarter of 2019 the sector also contributed $11.39 \%$ to the Nigerian Gross Domestic Product, representing a nominal value of N3,980,14 Billion (NCC Report, 2019). This study therefore seeks to evaluate how the outsourcing activities of the Nigerian Telecommunications sector impacts on their performance in recent years, taking a critical look at cost reduction, risk reduction, quality improvement and operational efficiency.

\subsection{Objectives of study}

This research seeks to evaluate the impact of outsourcing on the performance of the Nigeria telecommunications sector, specifically, the paper aims to:

i. Determine the extent to which Outsourcing core functions influence Cost Reduction in the Nigeria Telecommunications Sector

ii. Investigate which Outsourcing core functions influence Risk Reduction in the Nigeria Telecommunications Sector

iii. Examine whether Outsourcing core functions influence Quality Improvement in the Nigeria Telecommunications Sector

iv. Ascertain the extent to which Outsourcing core functions influence Organizational Efficiency in the Nigeria Telecommunications Sector

\section{4 Hypothesis of the study}

In line with the above objectives, the following null hypothesis are formulated

Ho1: There is no significant relationship between outsourcing core functions and cost reduction in the Nigeria Telecommunications Sector

Ho2: Outsourcing core functions does not significantly affect risk reduction in the Nigeria Telecommunication Sector

Ho3: Outsourcing core functions do not significantly influence quality improvement in the Nigeria Telecommunication Sector

Ho4: Outsourcing core functions do not significantly affect Organizational Efficiency in the Nigeria Telecommunication Sector. 


\section{Literature Review}

\subsection{Concept of Outsourcing}

There are many motives for outsourcing and it can either be strategic or operational. From the strategic view point, the outsourcing decisions must strategically align with the corporate objectives and from the operational perspective, considerations are given to tasks and activities that would generate high impact to the firm's performance. Zack (2005) argued that in adopting outsourcing strategy, such decisions must be broken into two key sub-decisions. According to him, the sub-decisions would emphatically address the issue of whether to outsource or not to outsource (sourcing governance-) and locational arrangements (Proximity). Sourcing governance means the systematic and simultaneous approach to managing the sourcing process, while proximity entails the locations and related arrangements.

Shy and Stenbacka, (2005) noted that firms are outsourcing to leverage on production, achieve economies of scale and lower cost. The position of Jiang and Qureshi, (2006) was not different as they noted that companies going for outsourcing decision also evaluate cost factor and if the reduction of the present operating cost is achievable through outsourcing, then it would be adopted to gain competitive advantage. However, according to Narayanan, (2009), he noted that outsourcing decisions is not solely to bring down cost but fundamentally to gain and maintain competitive advantage. He identified four (4) strategic reasons for outsourcing, which are improved cash flow, improved control of payment, scaling staffing and improve overall business performance.

Similarly, the workforce group identified the following five (5) key reasons why firms decides to outsource, cost savings, risk transfer, access to expertise, access to technology and focus on core competency. Kakumanu and Portanova, (2006) noted that outsourcing decisions varies across companies based on size and objectives, but cost factor has been dominating their basis for outsourcing decisions. This study has outsourcing as the independent variable with core functions as its proxy variable, and organizational performance as the dependent variable, with cost reduction, risk reduction, quality improvement and organizational efficiency as its proxy variables.

\subsubsection{Outsourcing and core competence}

The core competency theory posits that core functions should be retained and done in house by organizations. Simchi-Levi, Keminsky \& Simchi-Levi, (2004) defined core competency as the collective learning in the organization on how to coordinate diverse skills and integrate multiple streams of technology. Prahalad and Hamel (1990) identified core competency as a strategic tool of management, and further argued that to compete and attain sustainable competitive advantage, firms should build their business models, products and strategies around their core competencies, instead of blindly following competition. Imperatively, outsourcing decisions should be carefully thought out to ensure that all activities relating to the firm's core competencies are secured in-house. The main objective of the core competency perspective to outsourcing is to envelope sustainable competitive advantage, which outsourcing intends to achieve (Jae, et.at, 2006).

The core competency theory posits that core functions should be retained and done in house by organizations, while non- core functions are outsourced to free resources for value optimization. Reference to this research work, the core functions of the Nigeria telecommunications players are (Colocation, cloud services, connectivity services - Internet, leased circuits, Security and Wireless services, Enterprise voice, Business mobility - Mobile voice (Telephony) and data, - Hosting services - Video collaboration and Enterprise voice, Fiber optics service (FTTH), Business voice, Cloud service and email services).

\subsubsection{Outsourcing and Non-Core Functions}

Thompson et al. (2005) aees a firm's competency as a competitively valuable activity that a company performs better than its rivals (and which) represents competitively superior resource strength. The implication here is that the firm should protect its valuable asset. This is the position of the non-core competency theorist. According Sople (2004) noted that due to the pressure posed by competition, firms embraced outsourcing of non-core activities to outsiders that possesses expertise skills and knowledge with efficiency, effectiveness and at reduced cost. Firms also are aware of the risks posed by outsourcing which includes losing control of their valuable assets (expertise), and decided to retain the core functions in house while they outsource their non -core functions to remain competitive.

The non-core function theorist believes that outsourcing non-core functions would enable firms' concentrate on their core activities. In the Nigeria Telecommunications sector, the non-core functions are identified as the Human Resources (HR), ICT, Logistics, Fleet, and procurement, Financial Services, Tax Management and Legal Services. 


\section{1.3 Outsourcing and Performance}

According to Domiqueze, (2006), Quinn (1992), Gupta \& Zheuder, (1994) and Lever (1997), outsourcing can improve organizational performance when applied as organizational strategy. It is imperative to note that organizational performance can be measured both quantitatively and qualitatively. From the qualitative perspective, it may be subjective and factors such as customer satisfaction, workforce development, product quality, on time delivery, low churn rate, employee satisfaction etc. can be considered. Though subjective, but the following indices are used to measure non-financial performance (conversion rate, retention rate, customer satisfaction index, customer support tickets, product defect percentage, internal promotion rate, etc). However, factors such as Return on Assets, Return on Investment, Profitability etc., are used to measure financial performance. The major factors that influences outsourcing is Resources and Capabilities. The availability of human and material resource, and the capabilities of both resources (Human and Capital) would determine the extent outsourcing can be done and implemented successfully. This study would execute performance from cost reduction, risk reduction, quality improvement and organizational efficiency

\section{Cost Reduction}

Sparrow, (2005), Sahal \& Malhorta, (2005), and Kakabadse and Kakabadse, (2005), holds the view that cost reduction is the most important driver of outsourcing decisions. Notably, cost reduction had always been the primary motive behind outsourcing. As noted at the introductory section of this study, the response of firms that survived the economic recession and global economic meltdown was to transfer some of their services to external parties (outsourcing) as a means of lowering cost. Furthermore, Jiang and Qureshi (2006) noted that in making outsourcing decisions, companies evaluate the cost factor, and if the reduction in the present operating cost is achievable, then they would adopt the outsourcing decision. Interestingly, The study conducted by Sharma and Loh (2009) noted that firms that outsource for performance improvement motives saved 3.5times more than those that outsource for cost savings only. The position of Loh, 2009 was that cost reduction should no longer be the motive for outsourcing as taking other factors into consideration would naturally drive down cost and help the firm achieve efficiency.

\section{Risk Reduction}

As a general rule of the thumb, any business process that has benefit also has its potentials or associated risks. (Leavy, 2004, Arton et al, 2005, and Mihta et al. 2006) identified three (3) broad categories of outsourcing risks, which are: Operational risks, Strategic risks and other risks (culture and loss of client control) etc). (Mitchell, 1999) added psychological risks which is the frame of mind of the team or a manger responsible to manage an outsourcing activity, this is critical as it may make or mar the process, They all argued that if risk reduction is seen as the primary motive of outsourcing, it becomes easier to meet the desired organizational objectives. The Nigeria telecommunications sector operates within the Nigerian business environment and it is susceptible to potential business risks within the Nigerian business space. The KPMG 2018/2019 Business risk report identified the following 10 business risks that affects businesses in Nigeria.

Table 1 Ten (10) Top Business Risks in Nigeria

\begin{tabular}{|l|c|c|c|l|}
\hline Risks & $\begin{array}{c}\text { Risk } \\
\text { Benchmark }\end{array}$ & $\begin{array}{c}\text { Nig. Telecom } \\
\text { Risk Rating }\end{array}$ & Percentage & Impact \\
\hline Foreign Exchange Risk & 5.0 & 4.43 & 88.6 & High \\
\hline $\begin{array}{l}\text { Fiscal and Monetary Policy } \\
\text { Risk }\end{array}$ & 5.0 & 3.57 & 71.4 & High \\
\hline Regulatory Risks & 5.0 & 3.14 & 62.8 & Medium \\
\hline Crude Oil Price Risk & 5.0 & 3.57 & 71.4 & High \\
\hline $\begin{array}{l}\text { Brand and Reputational } \\
\text { Risks }\end{array}$ & 5.0 & 3.29 & 65.8 & Medium \\
\hline Customer Attrition Risks & 5.0 & 3.29 & 65.8 & Medium \\
\hline Political Risks & 5.0 & 3.00 & 60.0 & Medium \\
\hline Liquidity Risks & 5.0 & 2.57 & 51.4 & Medium \\
\hline Insecurity Risks & 5.0 & 3.43 & 68.6 & Medium \\
\hline Interest Rate Risks & 5.0 & 2.56 & 51.2 & Medium \\
\hline
\end{tabular}

Source (KPMG Business Risks in Nigeria, 2018/2019)

Legend: (3.50-5.0 High, 2.49-3.49 Medium and Less than 2.49 Low) 
The table 1 indicated that the Nigeria Telecommunications sector is exposed above average to the Ten (10) top business risks in Nigeria. The implication of this exposure underscores the importance that would be given to outsourcing (investment) decisions within the sector. Jiang and Qureshi(2006) noted that firms evaluate the cost factor and how it reduces present operating cost before embarking on outsourcing decisions, and this is also applicable to the Nigeria telecommunications sector under the risk challenges faced by the sector. Kremic et at. (2006) noted that despite the potential risks in outsourcing, for example security, cultural etc, firms still hopes to benefit from lower cost. The cost factor is a critical issue in outsourcing decisions.

Quality Improvement

Quality improvement can simply be seen as the positive transformation of a tangible item or service from its former stage or form to one, which is acceptable to consumers or users. Quality is subjective whether goods or service. Service quality can be described as customers' overall judgment or perception regarding a service (Parasuraman et al. 1988). It is important to note that although improvements can lead to changes, not only changes can lead to improvements.

As Kumar (2004) pointed out, service excellence has become the basic instinct and real value differentiator that drives client satisfaction. Operational excellence, product/service leadership and highly effective client relationship management are keys to assuring superior service delivery. Outsourcing decisions that are targeted at improving the quality of goods and services offered may achieve better result, because improvement is all encompassing, in a company's quest to achieve quality improvement, all other performance objectives may be achieved, as noted by Glodeswar \& Vaidyanathan (2008), Sharma and Loh, (2009,) and Arid \& Sappenfield, (2009) that key drivers of outsourcing includes reaching the global markets, and improving service quality, by implication when trying to reach the global market through outsourcing or improving quality service through outsourcing, the organizational objectives would be met.

\section{Organizational Efficiency}

Efficiency entails the obtaining maximum output with the use of the best minimum resources. Therefore, organizational efficiency is the ability of a firm to use the least possible input to obtain the greatest possible output. When outsourcing decisions of a firm leads to operational efficiency, it then means that the decision was carefully made to ensure that usage and allocation of resource was prudently done for the best value.

\subsubsection{Outsourcing and Performance in the Nigeria Telecommunications Sector}

The concept of this study focuses on the impact of outsourcing on the performance of the telecommunications sector in Nigeria. The research focused on a proxy variables' on outsourcing which is the Core functions. Specific to performance, the study focuses on four proxy variables which area Cost reduction, Risk reduction, Quality Improvement and Organizational Efficiency as presented in the figure 1 model below.

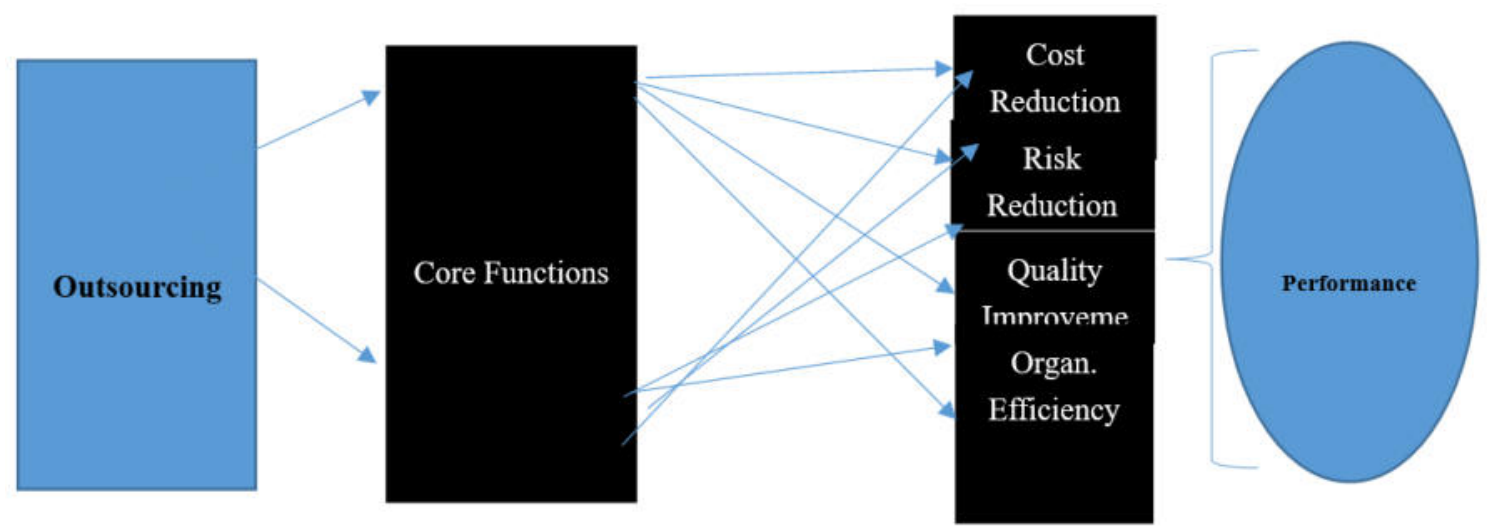

Figure 1: Conceptual Model of outsourcing and performance in the Nigeria telecommunications sector

\subsection{Theoretical Framework}

The concept of outsourcing and how it affect organizational performance has been reviewed based on different theories such as competency theory, resource based theory, transaction among other theories. In our studies, we found transaction cost more appealing to underpin the investigation. This theory supports the cost factors of 
outsourcing strategies. Sparrow, (2005), Sahal \& Malhorta, (2005), and Kakabadse and Kakabadse, (2005), who holds the transaction cost view noted that cost reduction is the most important driver of outsourcing decisions. The position of the transaction cost theory is that organizations should engage in outsourcing with the objective of lowering cost. Elan Bekeiv, (2012) sees transaction cost as the cost of negotiating, monitoring and governing exchanges between people. It should therefore be noted that the objective of the Transaction Cost approach is principally to minimize the cost of exchanging resources internally and externally. Since this theory views outsourcing from the transaction cost perspective, companies are encouraged to critical review their cost structure on exchanges and determine if the associated transaction cost would be lower before outsourcing.

Williamson, Oliver (1979) argues that the critical dimension for describing transaction are uncertainty, frequency, and the degree to which transaction, specific investment are required to realize least cost. Organization for Economic Corporation and Development (OECD), further align with Williamson with its definition of Transaction theory as cost involved in market exchange. Transaction theory is an economic theory that provide basis for make or buy decisions. Also, the Transaction cost theory noted that there are usually bureaucratic cost associated with transaction cost. The ability of the firms to minimize the bureaucratic cost would lead to efficiency of the process. The Nigeria telecommunications sector and the Nigerian business environment is not devoid of bureaucratic cost posed by political, economic and legislative bottlenecks of doing business in Nigeria. Also lack of expertise and low-level competent services providers could add to bureaucratic cost of doing business. Reference to the KPMG 2018/2019 Top ten (10) business risks in Nigeria and the level of exposures of the Nigeria communications sector on the risk matrix strongly underpins the importance of outsourcing decision, cueing from the Transaction Cost in making outsourcing decisions. It therefore becomes pertinent that industry players should ensure that in making outsourcing decisions, the perceived savings from the transaction costs is critically weighed against bureaucratic cost.

\subsection{Empirical Review}

Studies have been carried out globally on the impact of outsourcing on organizational performance in various sectors especially in service and manufacturing sectors. For instance, Khaki and Rusidi, (2012) conducted a study on the impact of outsourcing on the operational performance of the Iranian telecommunications sector taking a look at the impact on financial and non-financial factors. The outcome of the study indicated that outsourcing could lead to better financial and non-financial performance. While the study was considered useful, it was not able to clearly itemize what it considers non-financial performance. A similar study was conducted by Boison, et al. (2018) on assessing the impact of outsourcing on Vodafone Ghana, a West African country as Nigeria. The study looked at the impact of outsourcing on the quality of service, knowledge development and profitability, and found strong positive relationship between outsourcing and quality of service, and strong positive relationship between outsourcing and knowledge development, but could not find any relationship between outsourcing and profitability. Prince et al (2013) conducted a study on the impact of outsourcing non-core functions on selected hotels in Ghana. The outcome of the research study indicated that the hotels have been concentrating on their core functions in the areas of accommodation, food and bar services and housekeeping and have outsourced most of their non-core functions. The study also indicated that outsourcing non-core functions have been successful as it has impacted positively on the performance of the firm.

However, Ogunsanmi, (2013) specifically conducted a study on outsourcing practice and non-financial performance of Mobile Telephone service providers in Nigeria. The findings indicated that there is strong relationship between outsourcing and key performance indicators for assessing Mobile telephone operators in Nigeria, the study also noted that also that outsourcing has significant relationship with high churn rate in the industry. Similarly, Felix and Shale (2017) carried out studies on the impact of outsourcing on organizational performance in manufacturing sector in Kenya.. The study examined how outsourcing through cost reduction, quality improvement, technology adaptation and risk reduction impact on performance of an organization and found there was cost reduction, technology adaptation and quality improvement have significant positive relationships with performance, while there was a significant weak positive relationship between risk reduction and organizational performance,

\section{Methodology}

Descriptive research design was adopted based on the targeted population of 88 comprising of management and technical staff who play vital role in outsourcing decisions and monitoring outsourcing services from the four (4) operating mobile telephone companies in Nigeria. The four companies are: MTN, Globacom, Etisalat and Airtel). The study adopted census in which the 88 staff are the respondents. Kothari (2004) stated, that census method can be used when the population is small or when it is reasonable to include the entire population. A structured questionnaire with a number of options using a 4-point likert scale was administered through physical delivery and 
via emails for convenience. Structured questionnaires were used for data collection, and Statistical Package for Social Sciences (SPSS) tool was employed to analyze the data collected. In addition, regression analysis of the variables helped to establish the relationship between outsourcing Core functions, and performance of the organizations.

Table 2: Questionnaire distribution among respondents

\begin{tabular}{|l|r|r|r|r|r|r|r|}
\hline S/N & Engineering & Procurement & Logistics & Finance & Legal & Customer. Serv. & \multicolumn{1}{|c|}{ Total } \\
\hline Snr. Mgt & 8 & 8 & 8 & 8 & 4 & 8 & 44 \\
\hline Middle Mgt. & 8 & 8 & 8 & 8 & 4 & 8 & 44 \\
\hline & $\mathbf{1 6}$ & $\mathbf{1 6}$ & $\mathbf{1 6}$ & $\mathbf{1 6}$ & $\mathbf{8}$ & $\mathbf{1 6}$ & $\mathbf{8 8}$ \\
\hline
\end{tabular}

Source: Authors' computation

Table 1 shows the category of staff that the questionnaires were administered to, with total of 88 staff categorized into 44 Senior Management and 44 Middle Management staff. The structure of the companies indicated that a Director is responsible for a Directorate, which in some instances cuts across one or more function/department. The Management/Administrative structure has a General Manager responsible for each function and supported by a Senior Manager and Manager(s). Each company received 22 questionnaires totaling 88 questionnaires for the 4 companies. The distribution and collection was supported by two research assistants. A total of 57 correctly filled responses were received physically and via email representing $64.78 \%$ response. This response was considered good for analysis in line with the position of Mugenda and Mugenda, (1999) that, a response rate of 50\% is adequate for analysis, $60 \%$ good and above $70 \%$ is excellent for analysis.

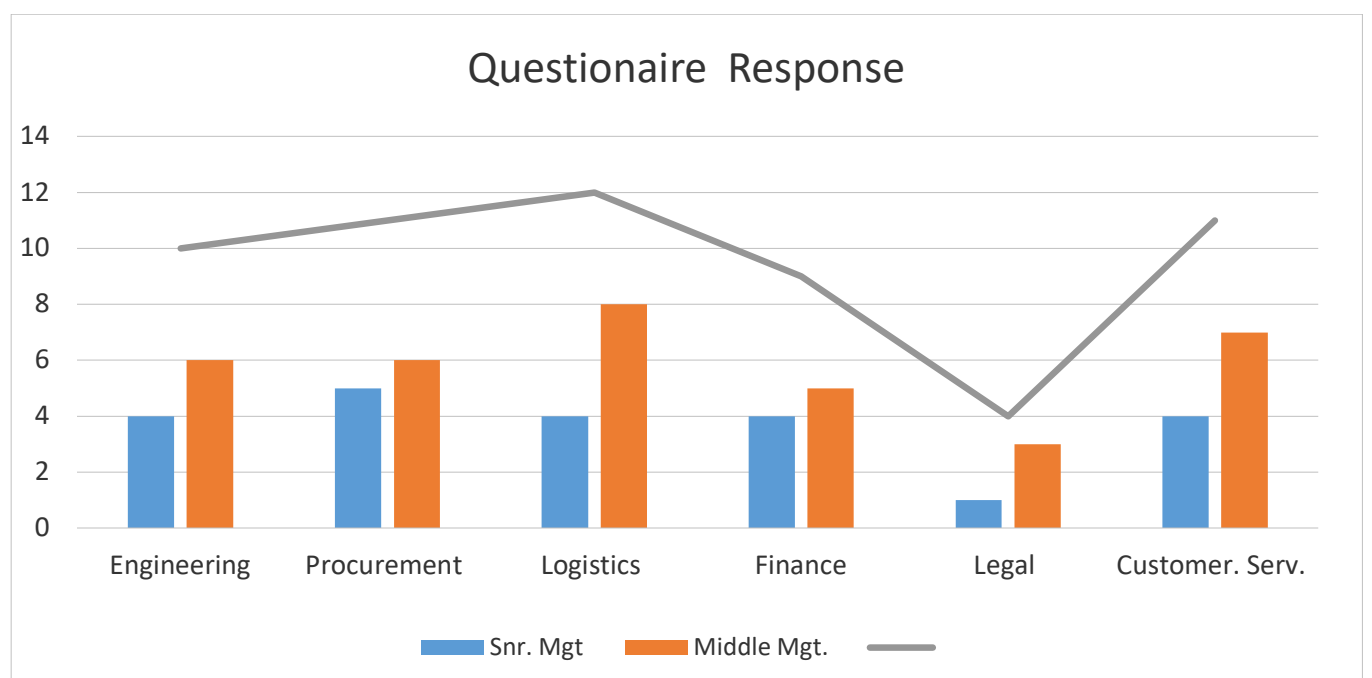

Figure 2: Bar Chart representation of questionnaire responses.

\subsection{Data Analysis And Results}

The research used regression method for data analysis. Regression analysis provides relationship between variables and among proxy variables. The study has outsourcing as independent variable and organizational performance as the dependent variables with cost reduction, risk reduction, quality improvement and operational efficiency as the proxy variables for the dependent variables, while core is the proxy variable for the independent variable.

Regression Analysis Error! Not a valid link. Source: Authors' computation (SPSS Version 21)

The study evaluated the extent to which outsourcing decisions influence performance in the Nigeria telecommunications sector specifically on Cost Reduction, Organizational efficiency, Quality Improvements and Risk Reductions. The analysis indicated that Cost Reduction has a strong positive relationship with Organizational Performance when outsourcing decisions of core functions are made, and it is also statistically significant with a (R-0.031 and P-value of .0.051). The implication of this result is that increase in cost reduction by the organization by 0.0331 units would also lead to an increase in organizational performance by same units, it can also be interpreted to mean that if organization reduce their cost by 0.031 or any percentage, through outsourcing decisions of core functions, the organization is also expected to improve performance by 0.031 or the same percentage. 
The analysis further indicated that, Organizational Efficiency and Quality Improvements with coefficient of 0.466 and 0.412 , respectively have weak positive relationship with organizational performance when outsourcing decisions are made at a P-Value of 0.055 and 0.076 , which also indicates that they are statistically significant. The implication of this result is that Organizational efficiency and Quality improvements policies such as quality assurance, Total Quality, Management quality control, prudent utilization of resources would weakly influence performance of the organization, positively when core functions are outsourced. The outcome of the study also indicated that Risk Reduction has a correlation R-value of 0.226 and P-Value of 0.276 , which indicates that Risk Reduction has a moderate positive relationship with Organizational performance when outsourcing decision of core functions are made.

The use of R-squared and the adjusted R-squared in data analysis is very critical. The R-Squared assumes every independent variable - Outsourcing in the model explains the variation in the dependent variable - Organizational Performance (Cost Reduction, Risk Reduction, Quality Improvement and Organizational Efficiency). It gives the percentage of explained variation as if all independent variables in the model affect the dependent variable. Adjusted R-squared, on the other hand, gives the percentage of variation explained by only those independent variables that, in reality, affect the dependent variable. $\mathrm{R}$-squared $\left(\mathrm{R}^{2}\right)$ and adjusted $\mathrm{R}$-square allow decision makers to measure the value of dependent variable -Organizational Performance against the value of the independent variable-Outsourcing a benchmark. Decision makers may use the calculation for policy formulation, planning and forecasting.

The result showed an adjusted R-Squared value of 0.799 which indicates the proportion of variance in Organizational performance that accounted for Cost Reduction, Organizational Efficiency, Risk Reduction and Quality Improvement, while R-Square value of 0.81, shows that proportion of variance in organizational performance is due to the interactions of the independent variable, taking into cognizance the degree of freedom (df). Notably, the F-Statistics of 76.96 gives us reasonable evidence that the parameters of the regressed model are jointly statistically significant, thereby validating the Adjusted R-Squared and the R-Squared. With the low probability value of $\mathrm{f}$-statistics $(0)$, it is therefore confident to state that the estimated model is fit for planning, policy formulation and forecasting.

\subsection{Test Of Hypothesis}

The outcome of the regression analysis above would be used to validate the null hypothesis for the study as already indicated in the paper.

Ho1: There is no significant relationship between outsourcing core functions and cost reduction in the Nigeria Telecommunications Sector

Validation: From the regression analysis in table three (3), the R-value for Cost Reduction was 0.031 which is a positive value, and by implication it therefore indicates that we will fail to accept the Null Hypothesis, and conclude that Cost Reduction positively influence Organizational Performance in the Nigeria Telecommunications Sector.

Ho2: Outsourcing core functions do not significantly affect risk reduction in the Nigeria Telecommunication Sector Validation: From the regression analysis in table three (3), the R-value for Organizational Efficiency Reduction was 0.466 which is a positive value, and by implication it therefore indicates that we will fail to accept the Null Hypothesis, and conclude that Organizational Efficiency positively influence Organizational Performance in the Nigeria Telecommunications Sector.

Ho3: Outsourcing core functions do not significantly influence quality improvement in the Nigeria Telecommunication Sector

Validation: From the regression analysis in table three (3), the R-value for Quality Improvements was 0.412 which is a positive value, and by implication it therefore indicates that we will fail to accept the Null Hypothesis, and conclude that Quality Improvements positively influence Organizational Performance in the Nigeria Telecommunications Sector.

Ho4: Outsourcing core functions do not significantly affect Organizational Efficiency in the Nigeria Telecommunication Sector

Validation: From the regression analysis in table three (3), the R-value for Risk Reduction was 0.226 which is a positive value, and by implication it therefore indicates that we will fail to accept the Null Hypothesis, and conclude that Risk Reduction influence Organizational Performance in the Nigeria Telecommunications Sector.

\section{Conclusion And Recommendations}

5.1 Conclusion

The role of the Nigeria telecommunications sector especially the mobile telephone operators to economic 
development are immeasurable. The Nigerian Communications commission (NCC) report indicates that the sectors contribute greatly to the Nigerian GDP over the years. The revolution of information technology and globalization has made practically all sectors to rely heavily on mobile telephony to perform one form of task or the other in Nigeria. Firms are advised to be conscious of the risk factors identified by the KPMG report, and ensure that outsourcing decisions are made taking into consideration each specific factor and how it relates to an outsourcing activity.

Critical to the Nigerian business environment is post contract management. It is therefore imperative to note that the success of outsourcing lies on the level of relationship between the client and the vendor. Webb and Laborde, (2005), noted that relationship and terms of engagements should be mutually understood agreed and accepted by both client and vendor to ensure a successful implementation of an outsourcing contract.

The result of the study showed a strong positive relationship between Cost Reduction and Performance, however, cost reduction should not the primary motive of outsourcing, Sharma and Loh (2009) noted cost savings has been argued as the primary motive behind outsourcing, however, despite spikes in cost savings, not all multinational companies that saved huge cost are now adopting cost savings strategy as the primary motive to outsource. The study also noted that firms that outsource for performance improvement motives saved 3.5times more than those that outsource for cost savings only.

\subsection{Recommendations}

Based on the findings of the study, the following recommendations are being made for the Nigerian Telecommunications Sector:

a) Outsourcing Decision makers should be conscious of the potential and inherent risks of outsourcing and urgently review the risk register and align it with the KPMG Nigeria top 1o business risk report, and ensure that proper risk evaluation are conducted before outsourcing decisions are made

b) Firms should de-empathized on immediate cost reduction when outsourcing, but look at the bigger picture such as access to global market, access to expertise, access to technology and note that firms that outsource with performance improvement as their primary objective save more than firms that outsource with cost savings as their primary objective. .

c) Outsourcing decision makers should pay greater attention to post contract relationship management. Relationship and terms of contract must be understood and agreed by all parties to reduce post award conflict

\section{Areas for Further Studies}

This paper evaluated the influence of outsourcing on organizational performance and restricted itself to qualitative performance indicators such as Risk reduction, cost reduction, quality improvement and organizational performance, but would expect to have a balanced view for future studies on financial performance indicators such as Return on Investment, (ROI), Return on Asset (ROA) Return on Equity(ROE).

\section{References}

[1] Akewushola and Elegbede (2013).Outsourcing Strategy and Organizational Performance: Empirical Evidence from Nigeria Manufacturing Sector. European Scientific Journal, 1259/1268.

[2] Barney, J., Wright, M. and Ketchen Jr, D.J.,(1991), The resource-based view of the firm: Ten years after 1991. Journal of management, 27(6), pp.625-641

[3] Branemo, A. (2006). "How Does the Industry Work with Sourcing Decisions? Case Study at Two Swedish Companies, "Journal of Manufacturing Technology Management, 17(5), 547-560.

[4] Boison, David King, Amedi, Senyo, Linda and Asiedu, Assessing the impact of outsourcing on organizational performance: A case study of Vodafone Ghana, International Journal of Social Sciences and Humanities Research 6(4) 2018, 1259-1267-(10)

[5] Charles K. (2016), "Outsourcing (Logistics) Services and Supply Chain Efficiency - A Critical Review of Outsourcing Function in Mukwano Group of Companies” Journal of Outsourcing \& Organizational Information Management, Vol. 2016 (2016), Article ID 937323, DOI: $10.5171 / 2016.937323$

[6] Dominguez, L (2006). The managers'step-by-step guide to outsourcing. Boston: McGraw Hill Companies. Foster, TA. (1999). Lessons learned. Logistics Management and Distribution Journal, 38(4), 67-69.

[7] Deloitte,(2014).“Global outsourcing and insourcing survey”, available at:www2.deloitte.com/us/destination.

[8] Fantazy, K. A., Kumar, V. \& Kumar, U. (2009). "An Empirical Study of the Relationships among Strategy, Flexibility, and Performance in the Supply Chain Context," Supply Chain Management: An International Journal, 14(3), 177-188.

[9] Felix Ndugu Kamanga and Shale Noor Ismail, 2007 ,Effects of outsourcing on organizational performance in Manufacturing Sector in Kenya, European Journal of Logistics, Purchasing and Supply Chain Management, Vol.5 No.5.pp52-79, December, 2017

[10] Handfield, R. (2012). A Brief History of Outsourcing. Retrieved on 19th October 2019 from $<$ icm.ncsu.edu/scm-articles/article/a-briefhistoryof-outsourcing.

[11] Handfield, R. (2006). A brief history of outsourcing. Supply Chain Management Journal. Vol. 5(2): 14-21.

[12] Harward, D. (2010). 4 Sourcing Strategies - Which is best for your business? https://www.trainingindustry.com/blog/outsourcing/4sourcing-strategies-which-is-best-for-your-business. retrieved on 21 Oct. 2019. 
[13] Heywood, S. Layton, D., Penttimen, R.A. better way to cut costs, McKinsey Global Survey Results, McKinsey Quarterly, 2008.

[14] Hoetler, G. (2005), "How much you know versus how well I know you: selecting a supplier for a technically innovative component", Strategic Management Journal, Vol. 26 No. 1, pp. 75-96.

[15] Isaksson, A, \& Lantz, B. (2015). Outsourcing strategies and their impact on financial performance in small manufacturing firms in Sweden International Journal of Business and Finance Research

[16] Irefin I.A, Olateju O.I \& Hammed G.O,(2012). Effect of Outsourcing Strategy on Project Success. Transnational Journal of Science and Technology July 2012 edition vol. 2, No.6

[17] Jae, NE, Minh, QH, Kwok, RC, Shih, MP (2000). The Evolution of outsourcing Research: What is the Next Issue. Proceedings of the 33rdHawai International Conference on System Sciences.

[18] Jiang, B \& Qureshi, A (2006) 'Research on outsourcing results: current literature and Future opportunities' Management Decision Vol. 44 No. 1 , pp. $44-55$

[19] Kothari, C. R. (2004). Research Methodology. New Delhi: New Age international. European Journal of Logistics, Purchasing and Supply Chain Management Vol.4, No.2, pp.1-10, April 2016

[20] Khaki, A.R. and Rashidi, S. (2012). Outsourcing and its impact on operational objectives and performance: a study of Iranian Telecommunication Industries. Management Science Letters, 2(2012), 235-244.

[21] KPMG (2018) Top ten (10) business risks, 2018/2019, home.kpmg/ng/en/home/insights/2018/04/top-10-business-risks-in-2018.html

[22] Kakabadse, A \& Kakabadse, N (2005) 'Outsourcing: Current and Future Trends'. Thunderbird International Business Review, Vol. 47(2) $183-204$

[23] Kakumanu,P \& Portanova, A (2006) 'Outsourcing: Its Benefits, Drawbacks and Other Related Issues.' Journal of American Academy of Business. Cambridge, Vol. 9 Issue 2

[24] Kotabe, Masaaki, Mol, Michael J., Murray, Janet Y. and Parente, Ronaldo. (2012) Outsourcing and its implications for market success: negative curvilinearity, firm resources, and competition. Academy of Marketing Science. Journal, Vol.40 (No.2). pp. 329-346. ISSN 0092-0703

[25] Kotabe, M, Murray, J, Javalagi, R. (1998). Global sourcing of service and market performance: An empirical investigation Journal of International Marketing, 6(4), 10-13.

[26] Kremic, T., Tukel, O.I \& Rom, W.O (2006) 'Outsourcing decision support: a survey of benefits, risks,and decision factors.' Supply Chain Management, Nov2006, Vol. 11 Issue 6, p467-482

[27] Leavy, B (2004) 'Outsourcing strategies: opportunities and risks', Strategy \& Leadership Journal, Vol. 32 No. 6,pp. 20-5

[28] Mugenda, J.M and Mugenda, A.G (1999), Research Methods, Nairobi: African Centre for Technology Studies. European Journal of Logistics, Purchasing and Supply Chain Management Vol.5 No.5, pp.52-79,

[29] Mehta, A., Armenakis, A., Mehta, N \& Irani, F (2006) 'Challenges and Opportunities of Business ProcessOutsourcing in India'. Journal of Labor Research, Vol. 27 Issue 3, p324-338

[30] Nazeri A. Gholami R \& Rashidi, S. (2012). Outsourcing and its impact on operational Performance Proceedings of the 2012International Conference on Industrial Engineering and Operations Management Istanbul, Turkey, July 3 - 6, 2012

[31] Narayanan, R. (2009) "In Search of Outsourcing Excellence" Supply Chain Management Review, 36-42.

[32] Nigeria Communications Commission [NCC], (2016), sector report pp1

[33] Nigeria Communications Commission [NCC], (2019), industry statistics

[34] MTN Nigeria [MTN],2017, Annual Report

[35] Ogunsanmi (2013), Outsourcing practice and performance of mobile telephone service providers in Nigeria, DBA Africa Review 3(2) 2013, 81-92-(8)

[36] Prahalad, C.K., Hamel, G (1990): The core competence of the corporation, Harvard Business Review, Vol. 68, No. 3, p79-91.

[37] Parasuraman, A., Zeithaml, V. \& Berry, L. L. (1988). Servqual: a multiple-item scale for measuring customer perception of service quality. Journal of Retailing, 64(1), 12-40.

[38] Priem, R.L. and Butler, J.E. (2001), "Is the resource-based view a useful perspective for strategic management research?" Academy of Management Review, Vol. 26 No. 1, pp.22-40.

[39] Quinn, JB (1992). Intelligent Enterprise: A knowledge and service based paradigm for industry. New York: Free Press.

[40] Sparrow, E. A (2005) 'A Guide to Global Sourcing: Offshore Outsourcing and Other Global Delivery Models'.Swindon BCS

[41] Sahgal, R \& Malhotra, V (2005) 'Moving offshore- Key Challenges and the Importance of quality Standards'. From ESOMAR, Annual Congress, Cannes

[42] Simchi-Levi, D., Ph. Kaminsky, \& E. Simchi-Levi, (2004), Managing the supply Chain: The Definitive Guide for the Business Professional, New York: McGraw-Hill.

[43] Sople, V.V. (2004). Logistics Management, Pearson Education Ltd.

[44] Shy, O \& Stenbacka, R (2005) 'Partial Outsourcing, monitoring cost, and market structure. Canadian Journal of Economics / Revue canadienne d'Economique, Vol. 38, No. 4

[45] Suraju, R.F. \& Hamed, A.B. (2013). Outsourcing services as a strategic tool for organizational performance: An exploratory study of Nigerian food, beverage, and tobacco industry. Journal of Management Policies and Practices 1(1); June 2013 pp. 01-20.

[46] Williamson, O.E. (1979), "Transaction-cost economics: the governance of contractual relations", The Journal of Law and Economics, Vol. 22 No. 3, pp. 233-261.

[47] Zack, M. (2005). 'The strategic advantage of knowledge and learning'. International Journal of Intellectual Capital and Learning, 2, 120 . 